Journal of Teaching and Learning with Technology, Vol. 10, Special Issue, pp. 386-389.

doi: 10.14434/jotlt.v9i2.31226

\title{
ZOOMing into a Community: Exploring Various Teaching Practices to Help Foster Sense of Community and Engagement in Emergency Remote Teaching
}

\author{
Nesrin Bakir \\ Illinois State University \\ nbakir@ilstu.edu \\ Krystle Phirangee \\ University of Toronto \\ krystle.phirangee@utoronto.ca
}

\begin{abstract}
Educators across the world have been forced to shift their courses online due to the COVID19 pandemic. As face-to-face courses become online courses during this unprecedented time, instructors are thrown into emergency remote teaching (ERT). Where online learning involves "experiences that are planned from the beginning and designed to be online, emergency remote teaching (ERT) is a temporary shift of instructional delivery to an alternate delivery mode due to crisis circumstances... [which], will return to that [original] format once the crisis or emergency has abated. (Hodges, Moore, Lockee, Trust, \& Bond, 2020)The instructional demands of ERT can be overwhelming in that many instructors are trying to navigate new online teaching approaches to ensure their students have a sense of community (SoC), that is a sense of belonging and interactivity, and are still engaged, motivated, and involved in the course. Zoom, a cloud-based video conferencing platform, has boomed in popularity, becoming the go-to tool many instructors use to host and facilitate their courses, as well as to ensure a SoC is fostered and maintained. Guided by the social constructivism theory and community of inquiry (CoI) model, this quick hits piece aims to answer the question: In what ways might Zoom foster and sustain a SoC community in ERT?
\end{abstract}

Keywords: Sense of Community, Emergency Remote Teaching, Teaching Practices

\section{Theoretical Framework}

For constructivism, learners construct their meaning and knowledge as they learn with others (Richardson, 2003). Interactions between learners are critical, and they are more likely to take place if the instructor has fostered an atmosphere of mutual trust and community in the class. This relates to the claim that "[s] uccessful online interactions with peers have been found to result in more effective learning" (Hiltz as cited in Thurston, 2005, p. 356). The community of inquiry (CoI) model outlines three elements necessary for creating and fostering a community of learners: cognitive presence, social presence, and teacher presence (Danaher, Hickery, Brown, Alice, \& Conway, 2007). In this model, the students, the course content, and the instructor play a central role in creating a community and are interdependent (Morgan, 2011). A community is critical in minimizing feelings of disconnection and isolation among students because it offers an opportunity for them to engage in camaraderie and social reinforcement (Conrad, 2005; Gallagher-LePak, Reilly, \& Killion, 2009). In addition, community also allows for deeper thinking (Hulon 2013; Larson \& Kieper, 2002) and better student outcomes (Liu, Magjuka, Bonk, \& Lee, 2007). Therefore, we believe that a SoC can be fostered in ERT if instructors create interactions aligned with Constructivism and the CoI model. The next section focuses on 
specific teaching practices coupled with tools built in Zoom that align with constructivism and the CoI model in hopes of fostering a SoC.

\section{Teaching Practices Promoting Interaction}

Conduct an icebreaker to support student introduction with nonverbal feedback, chat, and the whiteboard. This interaction provides students with an opportunity to meet and learn about their peers. It also gives instructors the opportunity to analyze and understand their students' learning needs. Some icebreaker ideas include:

- Two Truths and a Lie: This activity involves each student introducing themselves with two truths and a lie and their peers guessing the correct answers regarding the truths and lie. This is a simple yet entertaining activity that allows students to learn about their peers' interests and hobbies.

- Binge watching: Binge watching a TV series on Netflix, Prime, or AppleTV is happening a lot during this trying time. Ask students what they are currently watching, which will allow students to connect with their peers on mutual taste in shows and spark some fun, interesting conversations.

- Hidden gems: Have students share a hidden gem, such as a favorite travel destination, an unexpectedly yummy recipe, a self-care routine, etc. This allows students to connect on various levels and learn from each other's experiences.

Use think-pair-share with share screen and breakout rooms. Pose a question, scenario, or problem on share screen to students and allow them to think about it for a minute. Then, pair students up, assign them to breakout rooms, and broadcast the instructions through a message to all breakout rooms. Have students decide on who the representative would be for the pair. When students are ready or when the allotted time is up, close the breakout rooms and have students join the main room. Then, have the representatives start a discussion about the question, scenario, or problem. This interaction allows students to process and dissect their knowledge independently first while also providing an opportunity for them to collaborate and negotiate with a peer.

Implement a concept or mind map with breakout rooms and the whiteboard. Provide students with a list of terms, and then put students into groups using breakout rooms. Using the whiteboard, ask students to put the terms into a concept or mind map that clearly illustrates how all the terms are related. When students have completed the activity, remind them to take a screenshot to share with the class or submit for credit.

Conduct knowledge checks with polling or a true or false statement activity by using nonverbal feedback. This feedback can include: Yes/No buttons, the raised hand feature, and reactions. Provide students with a statement relating to a specific topic in the course, and display it using the shared screen. For example, students can then say "Yes" if they think the statement is true or "No" if they think the statement is false. Before revealing the answer, have students defend both positions. This allows them to engage with the content and renegotiate their understanding and biases about the topic. Note: Access to the nonverbal feedback feature may depend on your institution's Zoom plan.

Initiate brainstorm discussions with the gallery view and the chat. Try brainstorming by asking students a question in which they can all submit their thoughts in the chat or students can share their thoughts when you do a whip around using gallery view. Doing the whip around also allows students 
to pass if they do not have an answer at the moment. This encourages students to take their time to process a question or concept, as well as further fosters a safe and accommodating learning environment.

Host a jigsaw activity using back-to-back breakout room sessions in which students are put into small groups to discuss different but relate topics. The first small group- the focus group-has a specific topic for students to explore. Students will then be shuffled and rotated into the second group - the task group — in which there will be one student from each focus group tasked to complete an activity together. In the second group, each student will represent their focus group by sharing the key ideas from their focus group discussion and pulling it all together to complete a task.

Harness case studies to check students' application of ideas and concepts with breakout rooms. Provide students with a specific case study relating to a course topic using the shared screen. Then, put students into small groups using breakout rooms to discuss the case study in relation to the course topics. Ensure that you broadcast the case study through a message to all breakout rooms so students have the option to review it, if needed. Once the allotted time for the small group discussion is up, close the breakout rooms and bring students back into the main room to discuss the case study. Use the whiteboard to jot down ideas from the discussion, and allow all students to annotate. Both instructor and students can take a screenshot for reference later. The whiteboard also can be utilized to show step-by-step instructions and solutions to problems.

Prepare handouts for lectures and distribute them to students prior to lectures. These handouts will serve as an outline of notes for the lectures where students fill out the missing content as they listen to/watch the lectures. This activity can be applied to synchronous and asynchronous sessions. Students can submit their work at the end of each lecture for comprehension check and attendance. The share screen tool can be used to review assignments and give real-time feedback.

Incorporate minute papers (Angelo \& Cross, 1993) to have students reflect on their learning process and to check students' understanding of key concepts. At the end of the Zoom class, give students a minute to answer questions related to the class. Ask students to jot down the most important, interesting, challenging, confusing, or unclear points they have learned from the class. Students can then share their responses in a class discussion using the gallery view.

\section{Conclusion}

All of the teaching practices presented are aligned to create meaningful and engaging interactions among learners; that is learner-content interactions, learner-instructor interactions, and learner-learner interactions in ERT. This focus is important because it emphasizes a need to not assume online learning is the same as ERT and offers simple yet pedagogically sound ways to foster and maintain a SoC and interaction in ERT.

Journal of Teaching and Learning with Technology, Vol. 10, Special Issue, jotlt.indiana.edu 


\section{References}

Angelo, T. A., \& Cross, K. P. (1993). Classroom assessment techniques. San Francisco: Jossey-Bass.

Conrad, D. (2005). Building and maintaining community in cohort-based online learning. Journal of Distance Education, 20(1), 1-20. https:/ / files.eric.ed.gov/fulltext/EJ807822.pdf

Danaher, P. A., Hickery, A., Brown, A., \& Conway, J. M. (2007). Exploring elements for creating an online community of learners within a distance education course at the University of Southern Queensland. In R. Luppicini (Ed.), Online learning communities (pp. 219-240). Charlotte, NC: Information Age Publishing.

Gallagher-Lepak, S., Reilly, J., \& Killion, C. (2009). Nursing student perceptions of community in online learning. Contemporary Nurse: A Journal for the Australian Nursing Profession, 32, 133-146. DOI: $10.5172 /$ conu.32.1-2.133

Hodges, C., Moore, S., Lockee, B., Trust, T., \& Bond, A. (2020). The difference between emergency remote teaching and online learning. EDUCAUSE Review. Retrieved from https://er.educause.edu/articles/2020/3/the-difference-between-emergency-remoteteaching-and-online-learning

Hulon, S. (2013). Face-to-face discussions versus online threaded discussions: Can we have the best of both worlds? In R. McBride \& M. Searson (Eds.), Proceedings of society for information technology \& teacher education international conference 2013 (pp. 577-582). Chesapeake, VA: Association for the Advancement of Computing in Education.

Larson, B. E., \& Keiper, T. A. (2002). Classroom discussion and threaded electronic discussion: Learning in two arenas. Contemporary Issues in Technology and Teacher Education, 2(1), 4562. https:/ / citejournal.org/volume-2/issue-1-02/general/classroom-discussion-andthreaded-electronic-discussion-learning-in-two-arenas/

Morgan, T. (2011). Online classroom or community-in-the-making? Instructor conceptualizations and teaching presence in international online contexts. The Journal of Distance Education/Revue de l'Éducation à Distance, 25(1), 1-14. http://www.ijede.ca/index.php/jde/article/view/721/1269

Richardson, V. (2003). Constructive pedagogy. Teachers College Record, 105(9), 1623-1640. https://doi.org/10.1046/j.1467-9620.2003.00303.x

Thurston, A. (2005). Building online learning communities. Technology, Pedagogy and Education, 14(3), 353-369. https://doi.org/10.1080/14759390500200211 